an urban area of Northeastern Brazil. Ticks Tick Borne Dis. 2018;9:1494-8. https://doi.org/10.1016/j.ttbdis.2018.07.011

3. Labruna MB, Marcili A, Ogrzewalska M, Barros-Battesti DM, Dantas-Torres F, Fernandes AA, et al. New records and human parasitism by Ornithodoros mimon (Acari: Argasidae) in Brazil. J Med Entomol. 2014;51:283-7. https://doi.org/10.1603/ME13062

4. Muñoz-Leal S, Faccini-Martínez ÁA, Costa FB, Marcili A, Mesquita ETKC, Marques EP, et al. Isolation and molecular characterization of a relapsing fever Borrelia recovered from Ornithodoros rudis in Brazil. Ticks Tick Borne Dis. 2018;9:86471. https://doi.org/10.1016/j.ttbdis.2018.03.008

5. Parola P, Diatta G, Socolovschi C, Mediannikov O, Tall A, Bassene $\mathrm{H}$, et al. Tick-borne relapsing fever borreliosis, rural Senegal. Emerg Infect Dis. 2011;17:883-5. https://doi.org/10.3201/eid1705.100573

6. Chikeka I, Dumler JS. Neglected bacterial zoonoses. Clin Microbiol Infect. 2015;21:404-15. https:// doi.org/10.1016/ j.cmi.2015.04.022

7. Doltario AB, Menon LJB, Bollela VR, Martinez R, de Almeida E Araújo DC, da Fonseca BAL, et al. Malaria and other febrile diseases among travellers: the experience of a reference centre located outside the Brazilian Amazon Region. Malar J. 2016;15:294. https:/ / doi.org/10.1186/ s12936-016-1347-x

8. Moreira J, Bressan CS, Brasil P, Siqueira AM. Epidemiology of acute febrile illness in Latin America. Clin Microbiol Infect. 2018;24:827-35. https://doi.org/10.1016/ j.cmi.2018.05.001

9. Rath PM, Fehrenbach FJ, Rögler G, Pohle HD, Schönberg A. Relapsing fever and its serological discrimination from Lyme borreliosis. Infection. 1992;20:283-6. https:/ / doi.org/ 10.1007/BF01710797

10. de Oliveira SV, Faccini-Martínez ÁA, Cerutti Junior C. Lack of serological evidence for Lyme-like borreliosis in Brazil. Travel Med Infect Dis. 2018;26:62-3. https:/ / doi.org/ 10.1016/j.tmaid.2018.04.005

Address for correspondence: Sebastián Muñoz-Leal, Departamento de Patología y Medicina Preventiva, Facultad de Ciencias Veterinarias, Universidad de Concepción, Av. Vicente Méndez 595-Casilla 537, Chillán-Región de Nuble, Chile; email: sebamunoz@udec.cl

\section{Etiology of Severe Acute Respiratory Infections, Bangladesh, 2017}

\author{
Md R. Rahaman, Karen A. Alroy, \\ Chris A. Van Beneden, Michael S. Friedman, \\ Erin D. Kennedy, Mahmudur Rahman, \\ Arunmozhi Balajee, A.K.M. Muraduzzaman, \\ Tahmina Shirin, Meerjady S. Flora, \\ Eduardo Azziz-Baumgartner
}

\begin{abstract}
Author affiliations: The University of Adelaide, Adelaide, South Australia, Australia (M.R. Rahaman); Institute of Epidemiology, Disease Control, and Research, Dhaka (M.R. Rahaman, A.K.M. Muraduzzaman, T. Shirin, M.S. Flora); Centers for Disease Control and Prevention, Atlanta, Georgia, USA (K.A. Alroy, C.A. Van Beneden, M.S. Friedman, E.D. Kennedy, A. Balajee, E. Azziz-Baumgartner) icddr,b, Dhaka, Bangladesh (M.R. Rahman);
\end{abstract}

DOI: https://doi.org/10.3201/eid2701.201347

In April 2017, surveillance detected a surge in severe acute respiratory infections (SARI) in Bangladesh. We collected specimens from SARI patients and asymptomatic controls for analysis with multipathogen diagnostic tests. Influenza A(H1N1)pdm09 was associated with the SARI epidemic, suggesting that introducing vaccines and empiric antiviral drugs could be beneficial.

Tr n April 2017, the Institute of Epidemiology Disease Control and Research (IEDCR) in Bangladesh noted an $89 \%$ increase in severe acute respiratory infections (SARI) compared with April 2016 through the National Influenza Surveillance Bangladesh (NISB) at 10 tertiary-care hospitals. During April 10-June 21, 2017, we conducted a case-control study to ascertain the cause of the outbreak and its associated risk factors.

We defined a SARI case as acute respiratory illness in a patient within 10 days of onset, with history of fever and cough, and requiring hospitalization (1). We sought to enroll all adults $\geq 18$ years of age who were admitted to NISB hospitals with SARI. Staff screened patients for eligibility, obtained written informed consent, surveyed participants about demographics, and took combined nasal and throat swab samples. Patients who died in hospital wards before enrollment were ineligible. Within 2 days of case-patient enrollment, staff enrolled 2 asymptomatic controls, identified by convenience from the same hospitals' outpatient clinics, surveyed them, and took combined nasal and throat swab samples. Patients who had fever or respiratory symptoms in the previous 14 days were ineligible to serve as controls. Swab 
specimens from case-patients and controls were tested for viral, bacterial, and fungal nucleic acids using FTD Respiratory pathogens 33 real-time reverse transcription PCR (Fast Track Diagnostics, http:/ / www. fast-trackdiagnostics.com)(2).

We examined the association between SARI casestatus and sociodemographic characteristics, preexisting conditions, and pathogens detected through multivariate logistic regressions. The investigation was judged to be public health action by the institutional review boards of the IEDCR and US Centers for Disease Control and Prevention (approval no. IEDCR/IRB/2016/17).

We identified 79 eligible SARI case-patients and 158 eligible controls from 5 NISB hospitals (Figure). Of these, 73 (92\%) eligible patients and $146(92 \%)$ eligible controls consented to participate (Table). Case-patients were more likely than controls to be male $(89 \%$ vs. $77 \%$; p $=0.041$ by Fisher exact test) and have preexisting underlying chronic conditions $(47 \%$ vs. $25 \%$; $p=0.001)$, including asthma $(36 \%$ vs. $12 \% ; p=0.000)$ and allergies $(27 \%$ vs. $10 \% ; p=0.003)$ (Table). Although $34(47 \%)$ of casepatients were treated with antibiotics, none were treated with antiviral drugs.

Fifty-three $(73 \%)$ case-patients and $92(63 \%)$ controls tested positive for $\geq 1$ pathogens (Table). Among 53 test-positive case-patients, $18(25 \%)$ tested positive for influenza viruses (Figure), including 12 (67\%) for influenza $\mathrm{A}(\mathrm{H} 1 \mathrm{~N} 1)$ pdm09, 5 (28\%) for unsubtyped influenza A, and 1 (6\%) for influenza C. Among 92 test-positive controls, $8(5 \%)$ tested positive for influenza viruses (Figure), including $3(38 \%)$ for influenza $\mathrm{A}(\mathrm{H} 1 \mathrm{~N} 1), 4(50 \%)$ for unsubtyped influenza $\mathrm{A}$, and 2 $(25 \%)$ for influenza C, 1 of whom had a codetection of an unsubtyped influenza A virus.
Male sex (odds ratio [OR] 2.4, 95\% CI 1.0-5.4), $\geq 1$ preexisting conditions (OR 2.7, 95\% CI 1.5-4.8), asthma (OR 4.2, 95\% CI 2.1-8.4), and history of allergies (OR 3.1, 95\% CI 1.5-6.6) were more common among SARI case-patients than controls (Table). Any influenza virus (OR 5.7, 95\% CI 2.3-13.7; $p=0.000$ ), and influenza A(H1N1) specifically (OR 9.4, 95\% CI 2.6-34.4; p $=0.001$ ), was significantly associated with SARI status. Only influenza A(H1N1) (OR 11.4, 95\% CI 2.7-47.4) remained associated with case status.

The surge in SARI during April 2017 was attributable to influenza viruses. Although influenza epidemics in Bangladesh typically occur during May-September (6), our investigation suggests the 2017 season started a month early. The government of Bangladesh has purchased Northern Hemisphere formulation influenza vaccines for Hajjis (i.e., for persons entering Mecca) $(7,8)$ but does not otherwise have a vaccination policy because its possible benefit has not been shown in Bangladesh. Influenza vaccines are sporadically available in Bangladesh's private market but rarely used. Our findings suggest the potential utility of estimating the cost-benefit ratio of influenza vaccination among persons at high risk for SARI using Southern Hemisphere formulations, which incorporate the most current vaccine strains recommended by the World Health Organization (7) before the April-May start of the Bangladesh influenza season.

Patients with SARI were frequently prescribed antibiotics but not antiviral drugs. Whether antibiotics benefit SARI patients or solely drive antibiotic resistance is unclear; however, observational data suggest the benefit of empiric antiviral drugs to prevent influenza complications during epidemics (9). IEDCR recommended empiric treatment of
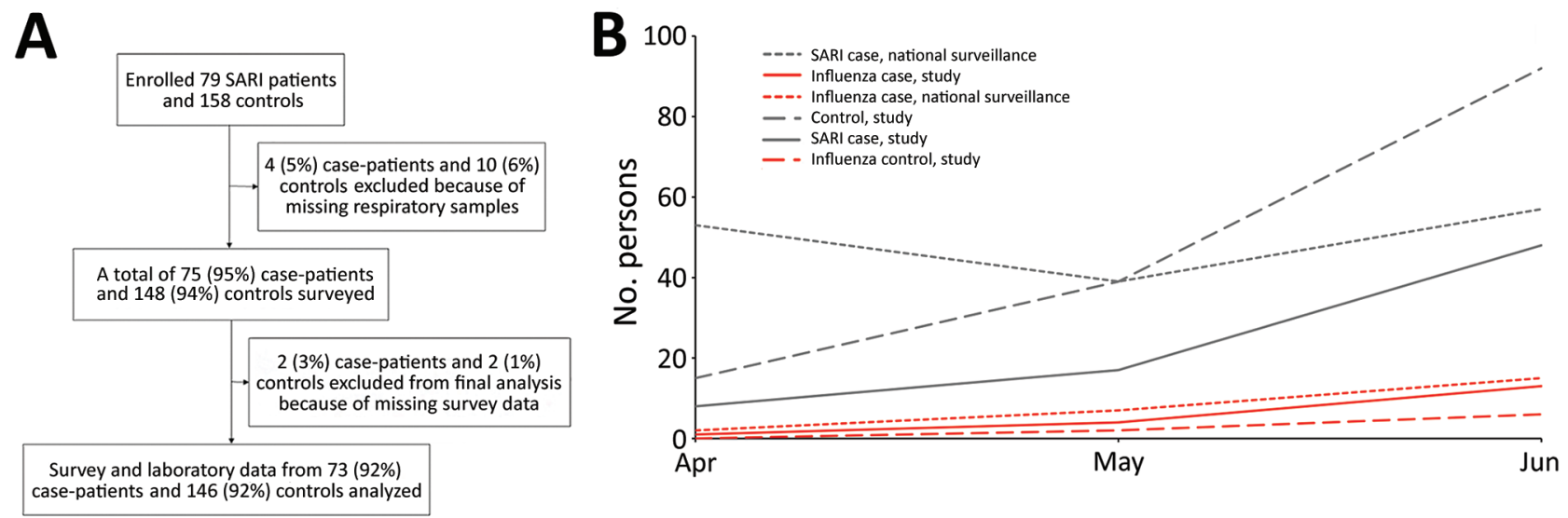

Figure. Participant enrollment in study of etiology of severe acute respiratory infections and influenza activities in Bangladesh, AprilJune, 2017. A) Enrollment of adults with severe acute respiratory infections (SARI) and their corresponding controls. B) Influenza activities, study (April 10-June 21) and national surveillance (April-June). Percentages might not sum to 100 because of rounding. 
patients with SARI with antiviral drugs during the 2009 pandemic but does not currently (10). Quantifiying the cost-effectiveness of empiric antiviral treatment for SARI patients during influenza epidemics could be valuable, particularly when used within 48 hours of symptom onset, when antivirals are most effective $(6,9)$.

This investigation had limitations. Controls were not randomly selected, and age and sex were not matched with case-patients. We limited our sample collection to the upper respiratory tract, did not have wells to identify influenza $\mathrm{A}(\mathrm{H} 3 \mathrm{~N} 2) \mathrm{RNA}$, and did not collect blood or other samples that would have more accurately detected bacterial infections.

Our investigation of a surge in SARI cases during April 2017 in Bangladesh suggests the value of surveillance and rapid response in identifying the etiology of outbreaks. Our findings also suggest the potential value of estimating the cost-effectiveness of influenza vaccination campaigns among groups at high risk for SARI administered as early as late March to early April and of empiric antivirals during Bangladesh's influenza epidemics.

\section{Acknowledgments}

We are grateful to all NISB surveillance staff including the IEDCR virology laboratory staff for their support in respiratory sample testing. We thank Mirza Mohammad Omer Farrque, and Jimmy Breen for their statistical input. We also thank Kaniz Fatema for help training NISB surveillance staff. We acknowledge the technical and editorial support provided by Lindsay Kim and Mary Ann Hall. Multipathogen diagnostic tests were provided by CDC's Division of Viral Diseases with support from the Global Health Security Agenda.

\section{About the Author}

Dr. Rahaman, a current PhD candidate at the University of Adelaide, is a medical doctor with specialist training in field epidemiology, international public health, and health management. His research interests include infectious disease epidemiology, particularly influenza; zoonoses, such as Q fever prevention; environmental epidemiology; and a One Health approach.

\section{References}

1. World Health Organization. A manual for estimating disease burden associated with seasonal influenza. Geneva: World Health Organization; 2015 [cited 2018 Oct 21]. https://www.who.int/influenza/resources/ publications/manual_burden_of_disease

2. Salez N, Vabret A, Leruez-Ville M, Andreoletti L, Carrat F, Renois F, et al. Evaluation of four commercial multiplex molecular tests for the diagnosis of acute respiratory infections. PLoS One. 2015;10:e0130378. https:/ / doi. org/10.1371/journal.pone.0130378

3. Staff correspondent. Bangladesh's per capita income rises to $\$ 1,314$. bdnews24.com. 2015 May 14 [cited 2019 Jan 13]. https://bdnews24.com/economy/2015/05/14/ bangladeshs-per-capita-income-rises-to-1314

4. Centers for Disease Control and Prevention. About adult BMI: how is BMI interpreted for adults? 2017 Aug 29 [cited 2017 Sep 20]. https://www.cdc.gov/healthyweight/ assessing/bmi/adult_bmi/index.html

5. Huque R, Zaman MM, Huq SM, Sinha DN. Smokeless tobacco and public health in Bangladesh. Indian J Public Health. 2017;61(Suppl 1):S18-24. https:/ / doi.org/10.4103/ ijph.IJPH_233_17

6. Zaman RU, Alamgir AS, Rahman M, Azziz-Baumgartner E, Gurley ES, Sharker MAY, et al. Influenza in outpatient ILI case-patients in national hospital-based surveillance, Bangladesh, 2007-2008. PLoS One. 2009;4:e8452. https:// doi.org/10.1371/journal.pone.0008452

7. Hirve S, Newman LP, Paget J, Azziz-Baumgartner E, Fitzner J, Bhat N, et al. Influenza seasonality in the tropics and subtropics - when to vaccinate? PLoS One. 2016;11:e0153003. https:/ / doi.org/10.1371/journal.pone.0153003

8. Saha S, Chadha M, Al Mamun A, Rahman M, Sturm-Ramirez K, Chittaganpitch $\mathrm{M}$, et al. Influenza seasonality and vaccination timing in tropical and subtropical areas of southern and south-eastern Asia. Bull World Health Organ. 2014;92:318-30. https://doi.org/10.2471/BLT.13.124412

9. Muthuri SG, Venkatesan S, Myles PR, Leonardi-Bee J, Al Khuwaitir TSA, Al Mamun A, et al.; PRIDE Consortium Investigators. Effectiveness of neuraminidase inhibitors in reducing mortality in patients admitted to hospital with influenza A H1N1pdm09 virus infection: a meta-analysis of individual participant data. Lancet Respir Med. 2014;2:395404. https:/ / doi.org/10.1016/S2213-2600(14)70041-4

10. Chowdhury F, Sturm-Ramirez K, Mamun AA, Iuliano AD, Bhuiyan MU, Chisti MJ, et al. Factors driving customers to seek health care from pharmacies for acute respiratory illness and treatment recommendations from drug sellers in Dhaka city, Bangladesh. Patient Prefer Adherence. 2017;11:479-86. https://doi.org/10.2147/PPA.S121800

Address for correspondence: Md Rezanur Rahaman, School of Public Health, The University of Adelaide, AHMS Building, 4 North Terrace, Adelaide, South Australia 5000, Australia; email: mdrezanur.rahaman@adelaide.edu.au 